\title{
Insurance and the Fixed Income Capital Markets
}

\author{
Y.C. $\mathrm{Wu}^{\mathrm{a}}$ and David Soanes ${ }^{\mathrm{b}}$ \\ ${ }^{a}$ UBS Investment Bank, Asset-Backed Finance, 1285 Avenue of Americas, 11th Floor, New York, NY \\ 10019, U.S.A. \\ E-mail: yi-cheng.wu@ubs.com \\ ${ }^{\mathrm{b}}$ UBS Investment Bank, Financial Institutions Group, 1 Finsbury Avenue, London EC2M 2PP, U.K. \\ E-mail: david.soanes@ubs.com
}

This paper firstly reviews the recent robust market performance of insurance financings and insurance-linked securities, covering traditional senior and subordinated/hybrid debt, as well as real risk transfer transactions. Secondly, we detail the five main categories of insurance securitizations. They represent the key recent developments of insurance securitization, allowing issuers to use innovative capital markets solutions to achieve strategic and financial objectives through these various forms of securitization.

The Geneva Papers (2007) 32, 46-57. doi:10.1057/palgrave.gpp.2510117

Keywords: securitization; embedded value; catastrophe; subordinated; sidecars; trigger

\section{Introduction}

One of the many advantages of commenting on the capital markets is their continuous development. During the May 2006 General Assembly of the Geneva Association, the markets were entering a period of some volatility. Volatility has been a recurring challenge to the development of insurance financing and linked securities; however, this latest bout of febrile conditions was met robustly.

Taking the senior debt and hybrid capital markets first, in May, the differential between bank and insurance spreads had narrowed consistently during the equity bull market phase that was established in June 2003. May and June 2006 were very testing times for capital markets, yet insurance spreads held up very well in absolute terms and relative to banks.

Although insurance paper widened more than bank spreads and has been somewhat slower to recover, this underperformance has been very modest and has not in any way reduced access to the capital market for insurers. The April/June 2003 spike shows how volatile this relative spread has been in the recent past (see Graph 1).

A good example of this strength in adversity is Generali. They issued three tranches of perpetual paper in the Eurobond market on 7th June, 2006, raising $€ 1.95$ billion and $£ 350$ million. This was competitively priced against a backdrop of very weak stock markets (the recent stock market low was attained on June 13) and considerable competing bank Tier 1 supply.

The U.S. capital market has been battling with increased stock volatility, rate uncertainty and the NAIC. The NAIC's approach to bank and insurance hybrid instruments has led to some spread weakness. Yet the market has remained open 


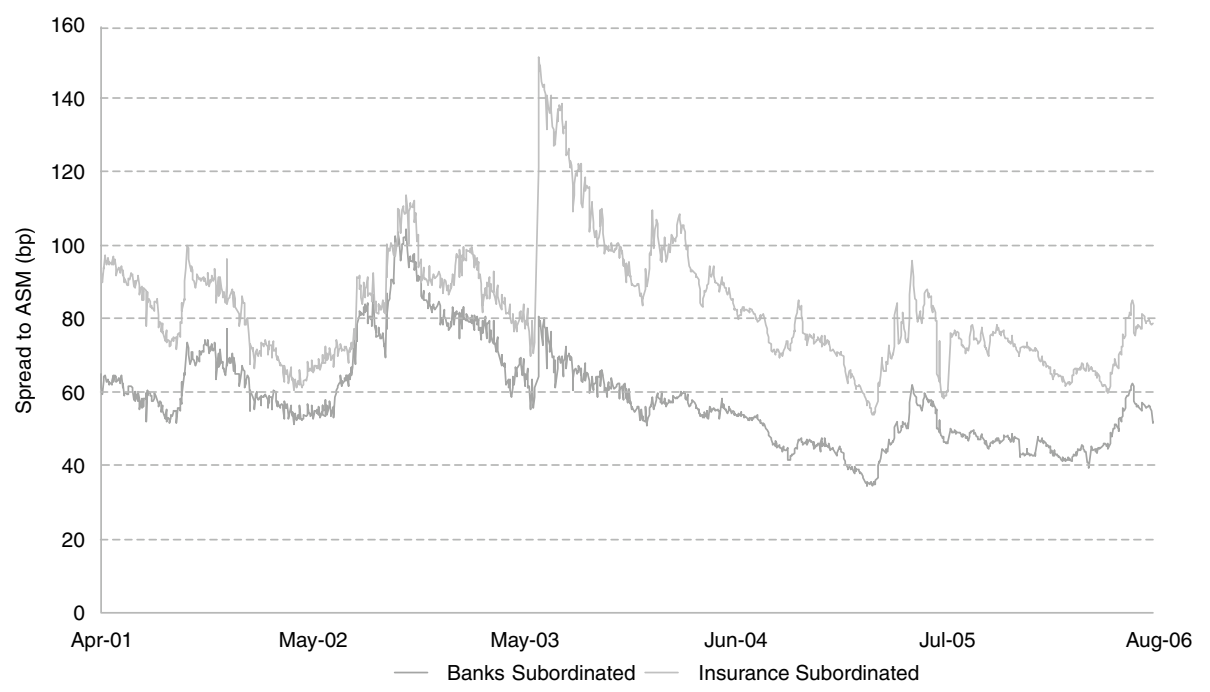

Graph 1. Banks versus insurers: subordinated debt.

(witness Swiss Re's US\$750 million perpetual issue) and has traded well (Swiss Re's issue has maintained its relative value). Swiss Re's Euro transaction, launched at the same time, has traded in a narrow range as well. Thus, the fixed income capital raising market has shown greater resilience than many expected - allowing issuers to have greater confidence that markets will be available when they want to issue.

More importantly, the market's appetite for absorbing real insurance risks has continued to grow. This is best underlined by a groundbreaking transaction from Swiss Re. The deal, at $\$ 950$ million, is the largest single bond sale from a Catastrophe bond programme. The securitization, called Successor, covers Japanese and California earthquakes, North Atlantic hurricanes and European windstorms risk. This continues Swiss Re's innovation and leadership in this market both as an issuer and as an advisor. As an advisor, Swiss Re Capital Markets were a lead manager for Liberty Mutual's \$200 million BB + protection against hurricanes in the north-east of the U.S., covering all states bordering the Atlantic from Maryland to Maine, as well as Vermont and Washington DC.

The above developments, coupled with $\mathrm{XXX} / \mathrm{AXXX}$ redundant reserve securitization, EV transactions, AXA's motor transaction and continued investment by issuers, investment banks and investors, is fuelling growth and innovation.

Since the 1980s, commercial banks have successfully used securitization to enhance their financial performance and embraced securitization as a necessary financing tool to manage their capital structure. Recently, the insurance industry has also looked to the capital markets to unlock the value of certain business, free up redundant reserves or perform risk management as an alternative risk transfer mechanism.

There are five main categories of insurance securitizations. They represent the key recent developments of insurance securitization, allowing issuers to use innovative 
capital markets solutions to achieve strategic and financial objectives through these various forms of securitization.

\section{Triple X and AXXX redundant reserve securitizations}

Regulation Triple-X, also known as Valuation of Life Insurance Model Regulation XXX, went into effect for U.S. life insurance and reinsurance companies in 2000 . Regulation Triple-X defines reserving methodology for companies that underwrite guaranteed term life policies in the U.S. AXXX, also known as Actuarial Guideline 38 (AG 38), clarifies reserving methodology for universal life (UL) products with nonlapse secondary guarantees. The statutory reserve formula under Regulation Triple-X and AG 38 created redundant statutory reserve requirements for life companies. They are formula-based calculation using a standard mortality valuation table that is considered to be overly conservative (e.g., the 1980 CSO Table), which ignores 30 years' mortality improvements in the U.S. insured population and does not adjust for any variance in mortality experience among different classes of risks (e.g., preferred versus standard risks).

In addition, for universal life policies writers, conservative valuation assumptions under AG38 created similar redundant statutory reserve requirements versus the CRVM reserves.

The sophisticated insurance underwriting technology adopted by the insurance industry when underwriting life insurance risks provides for a basis to calculate the socalled "economic" reserves that are based on their best estimate actuarial assumptions. The difference between statutory reserves and economic reserves are the redundant reserves (see Graphs 2 and 3 showing the "humped" shape trajectory of the XXX and AXXX statutory reserves versus the economic reserves over the life of a term life or UL policy). For companies that focus on underwriting "preferred" or "superpreferred" risks, the redundant reserve requirements could be multiples of what the economic reserves are.

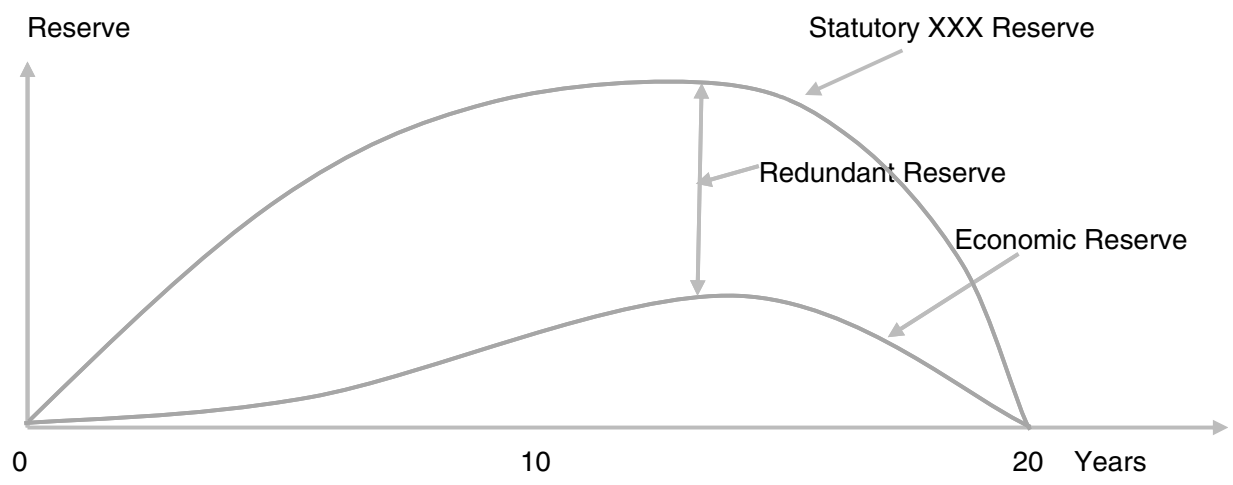

Graph 2. Illustration of XXX redundant reserves. Source: Moody's. Based on a 20-year term policy issued to a male-preferred non-smoker, aged 45 . 


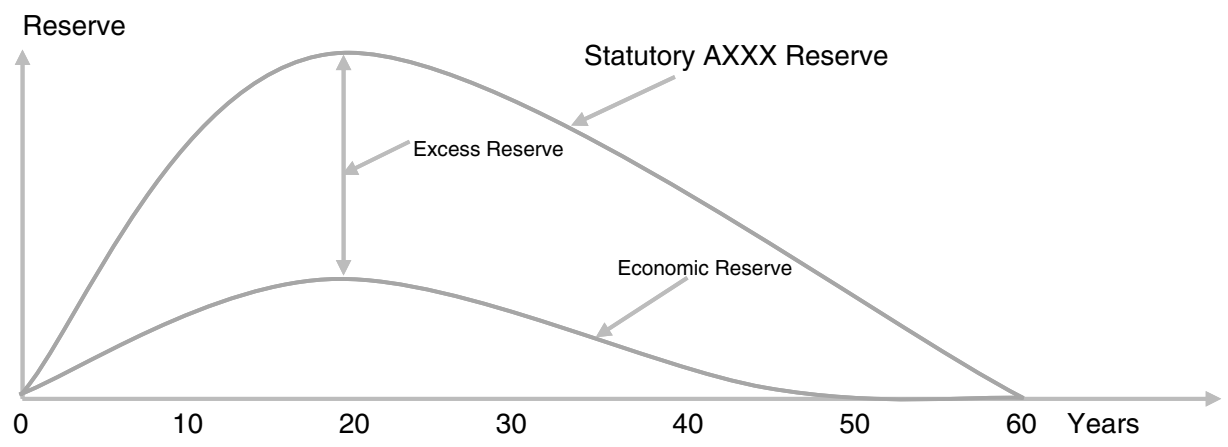

Graph 3. Illustration of AXXX redundant reserves. Source: Moody's. Reflects one year of production for a hypothetical portfolio of UL secondary guarantee business.

Since the adoption of Regulation Triple-X and AG38, U.S. life insurance companies have sought primarily short-term funding solutions for the redundant reserves by ceding the businesses to reinsurers who then collateralize the reinsurance obligations with a letter of credit (LOC) issued by a bank. The costs of such LOCs have increased significantly as the reserve requirements increase over time, and this has caused reinsurance premiums to increase. LOCs are also subject to renewal risks and therefore such short-term solutions have been criticized by rating agencies as not being good asset-liability management practices. Triple-X and AXXX securitizations are attempts by life insurance companies and reinsurers to fund redundant reserves via capital markets:

- the theme is collateral financing to obtain reserve credit;

- low cost/non-recourse financing is the key funding objective;

- only transfer very remote mortality risks (out-of-money option) to investors;

- transactions typically "wrapped" by one or more AAA-rated financial guarantors;

- securitization, therefore, provides a "permanent" solution to redundant reserve requirements.

Since 2003, over $\$ 8.7$ billion XXX securitizations have been completed. AXXX securitization is imminent with the first-ever AXXX transaction expected to come to the market in the latter part of 2006. Various estimates put the redundant reserve funding needs of U.S. life insurance companies and reinsurers at $\$ 100$ to $\$ 200$ billion by 2015 , indicating more companies may be motivated to pursue capital markets solutions for the redundant reserve requirements.

Figures 1 and 2 illustrate two generic structures for a Triple-X securitization transaction - the "upstream" structure versus the "downstream" structure. In both structures, a block of life insurance policies is co-insured into a special purpose reinsurer (the "SPV"), so that its risks can be analyzed independently by third-party investors, actuarial consultants, the rating agencies and the financial guarantor providing the wrap to bond investors. The ring-fenced structures segregate the insurance risks from the credit risks of the insurance underwriter and therefore allow 


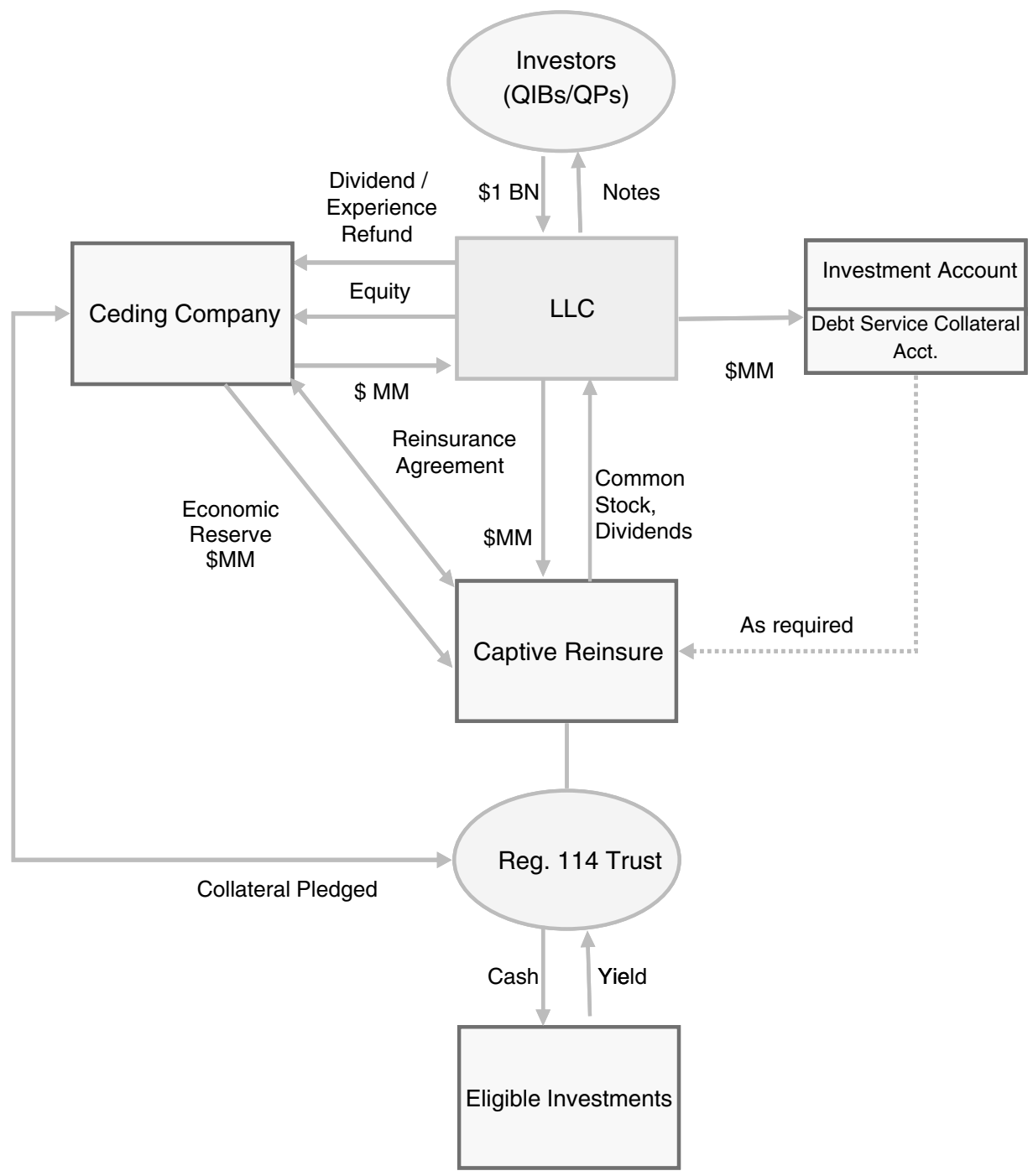

Figure 1. Triple-X "Upstream” transaction structure (used by RGA and Scottish Re).

the financing to be treated as non-course debts of the sponsor (i.e., the ceding insurer or reinsurer) of the securitization. The sponsor or the ceding company will need to have "skin in game" by providing the economic capital (i.e., economic reserves and equity capital for the SPV). Securitization helps the insurance company secure a permanent source of financing with locked-in cost of capital, maximum flexibility and potential tax benefits. It also rewards companies that have greater pricing discipline and underwriting practices as they will have better access to capital markets. In the long run, securitization will help the sponsors of these transactions to enhance their financial performance and improve their market position. 


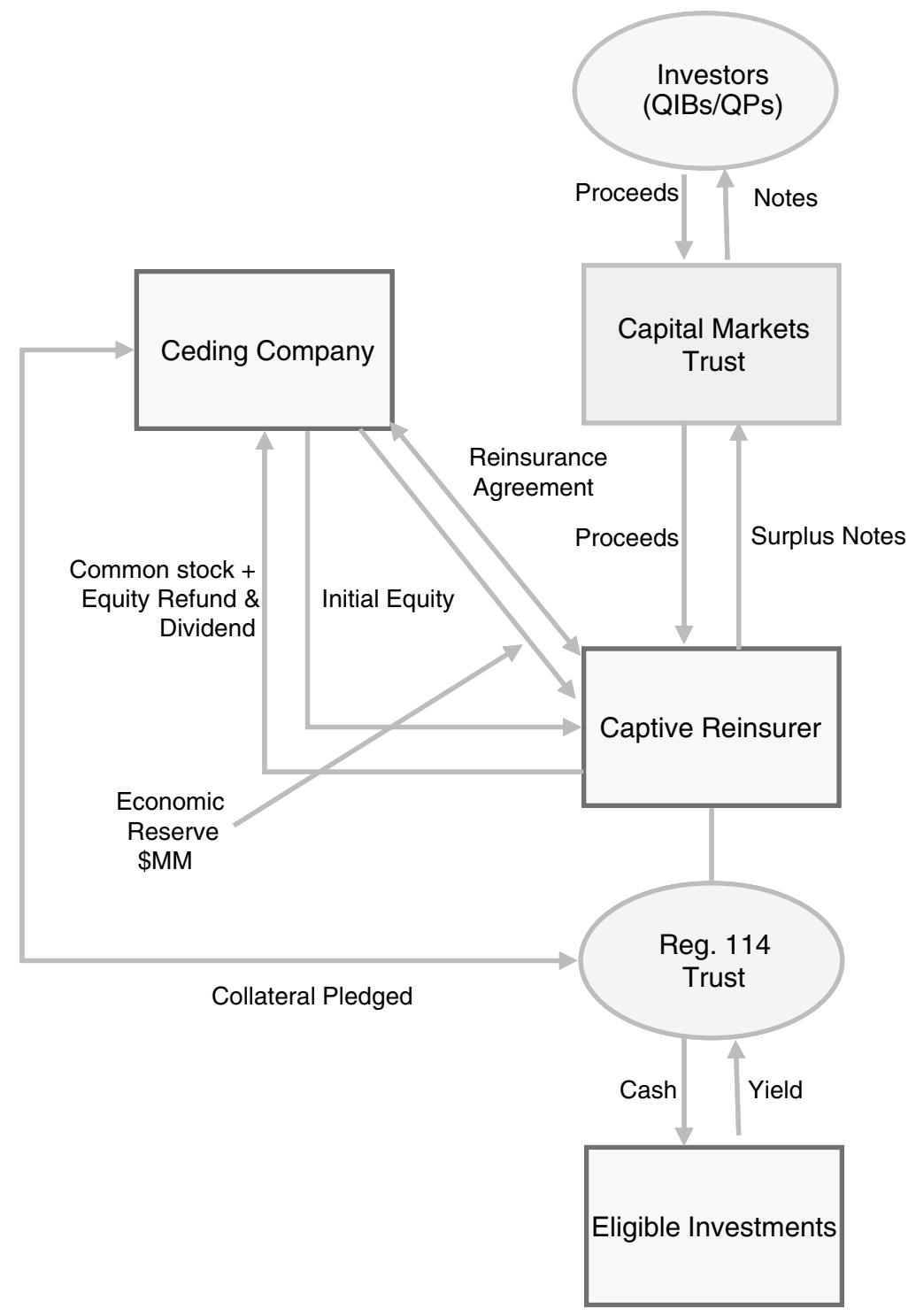

Figure 2. Triple-X "Downstream" transaction structure (used by Genworth Financial/First Colony).

\section{Embedded value securitization}

Embedded value ("EV") securitization involves transactions where insurance companies monetize future profits emerging from a block of business. It often involves a seasoned closed block of life insurance business in run-off. Such blocks of businesses provide for stable cash flows with predictable range of profitability based on their future performance and therefore are most suitable for securitization (see Figure 3). 


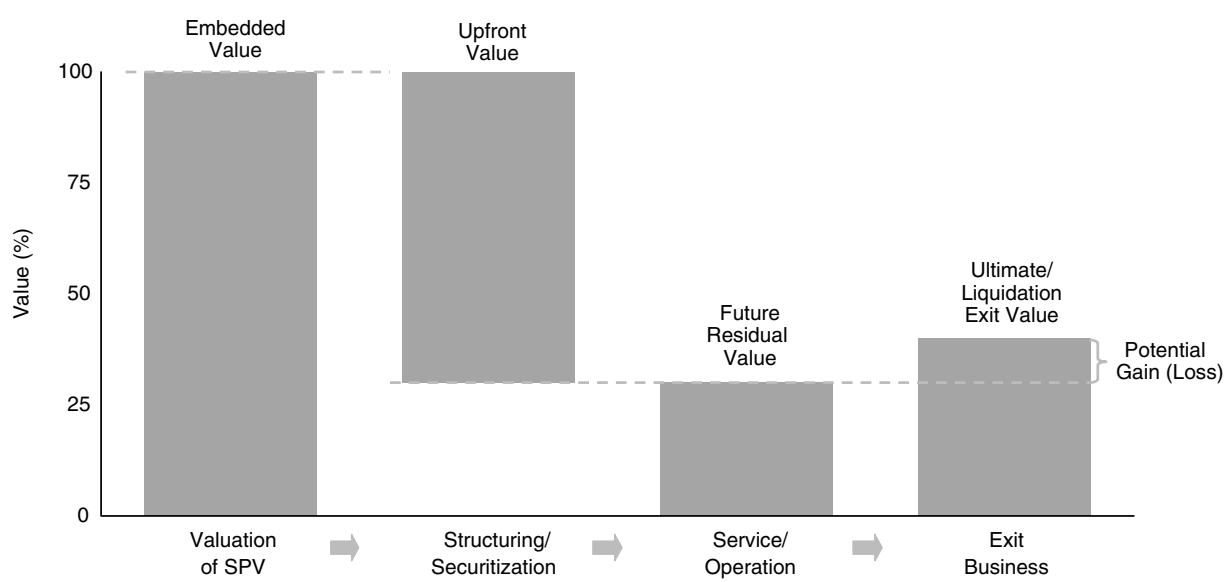

Figure 3. Embedded value monetization (issuer perspective).

EV securitization provides an alternative source of capital to insurance companies with the following main benefits:

- freeing up excess capital trapped in the securitized block;

- funding new business strains;

- providing non-recourse financing/low cost of capital;

- redeployment of capital from the "low-beta" business to invest in higher return businesses to enhance the company's overall ROE;

- enhancing and demonstrating balance-sheet liquidity, that is, "acceleration" of balance sheet.

As a contrast to the Triple-X/AXXX securitization, where sourcing cheap collateral to fund redundant reserves from capital markets is the main financing objective, risk transfer can be an important benefit of an EV securitization. In an EV securitization, investors are exposed to actuarial risks embedded in the subject business being securitized, including:

- mortality/longevity risks;

- lapse risks;

- investment risks.

Since 1996 over \$7 billion in embedded value securities have been sold to the capital markets and the investors have grown in terms of their appetite for insurance-linked investments (see Graph 4).

Figure 4 shows a generic EV securitization structure. Similar to the Triple-X/AXXX securitization, a block of business is co-insured into an SPV to segregate the insurance risks from the sponsor's corporate credit risks.

\section{CAT bonds}

Catastrophe (CAT) bonds originated from the reinsurance pricing and capacity crisis that followed Hurricane Andrew (\$18 billion in claims) and Northridge earthquake in 


\begin{tabular}{lccl} 
Transaction & Year & Size $(\mathbf{m m})$ & Sponsor \\
\hline ALPS & 2005 & $\$ 370$ & Swiss Re \\
Queensgate & 2005 & $\$ 245$ & Swiss Re \\
Forethought & 2004 & $\$ 150$ & The Devlin Group \\
Box Hill & 2004 & $\$ 726$ & Friends Provident \\
Gracechurch & 2003 & $\$ 679$ & Barclays/Gracechurch \\
MONY & 2002 & $\$ 450$ facility $(\$ 300)$ & AXA/MONY \\
Prudential Holdings & 2001 & $\$ 1,750$ & Prudential Financial \\
L1- L6 & $1998-2006$ & $£ 829$ & Hanover Re \\
Mutual Securitization & 1998 & $£ 260$ & NPI \\
ASLAC Funding Trust 1- & $1996-2001$ & $\$ 411$ & American Skandia \\
13 & & & \\
\hline
\end{tabular}

Graph 4. Size of EV securities since 1996.

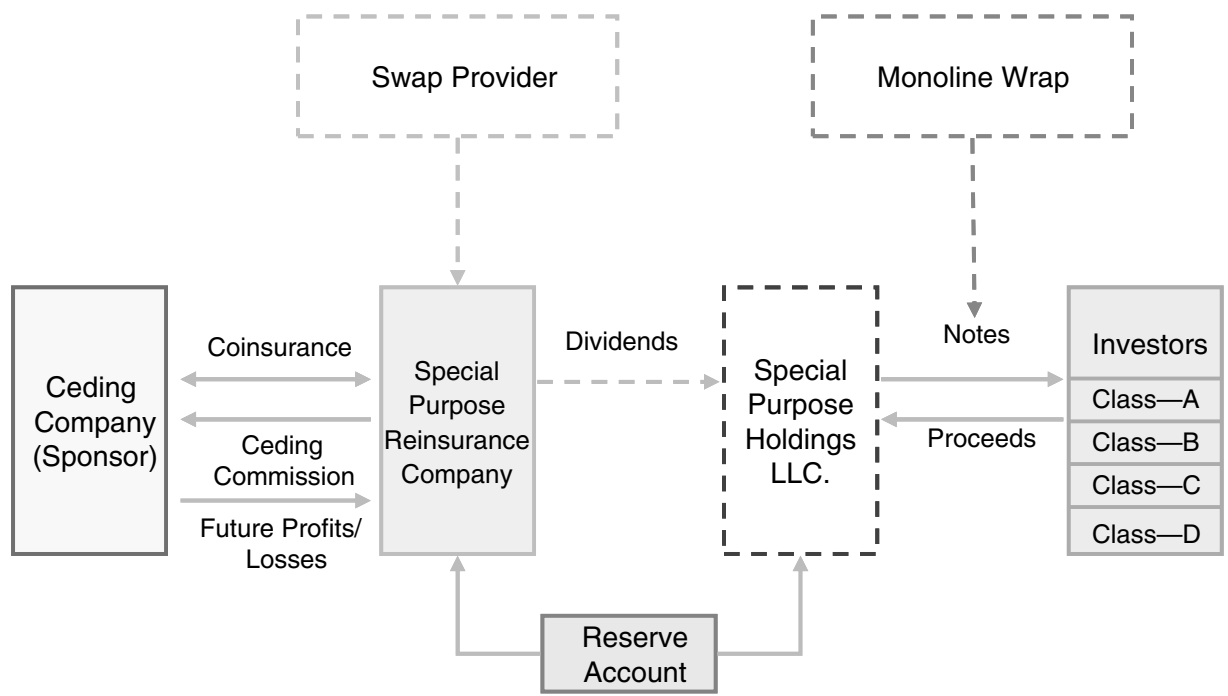

Figure 4. Generic schematic EV securitization transaction structure.

California (\$11 billion in claims) in the early 1990s. These issues are a direct result of the following factors:

- rising population density in heavily insured areas: California, Texas and Florida and their surrounding areas;

- inflation of property values;

- increased penetration of $\mathrm{P} / \mathrm{C}$ insurance.

Current industry risk books abound with exposures to the following:

- California earthquakes;

- Southeastern U.S. hurricanes;

- European windstorm and flood;

- Japanese earthquake and typhoon. 


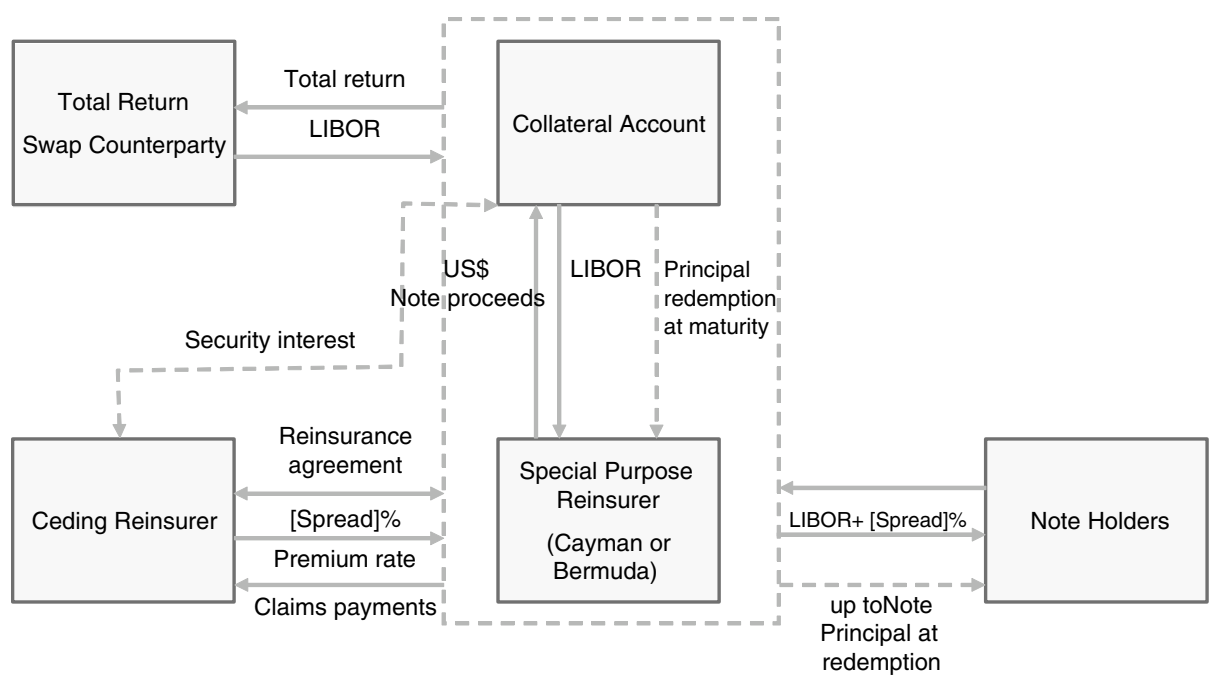

Figure 5. General schematic structure of a CAT bond.

From an issuer perspective, $\mathrm{P} \& \mathrm{C}$ companies sought to increase retrocession capacity and avoid pricing volatility due to catastrophic events through the capital markets. Risk transfer is the primary objective of issuing CAT bonds. In addition, the collateralized transaction structure of CAT bonds removes counterparty credit exposure to the reinsurer.

From an investor perspective, CAT bonds offer attractive yields for investors who want to diversify their investments. Ratings and yield can be tailored to CAT bonds investor needs (i.e., reverse inquiry). CAT bonds' yields and issuance volume generally follow reinsurance capacity cycle. Investors have, therefore, become very opportunistic in terms of timing and yield demand to maximize risk-reward trade off (see Figure 5).

There are currently three types of CAT bonds:

(1) Indemnity notes: In these notes, notes pay-out mirrors precisely the ceding insurers' losses, subject to the attachment point being reached. There needs to be minimum disclosure of the ceding insurer's underwriting data. Investors may also be subject to lengthy insurer loss development periods in the form of maturity extension.

(2) Indexed notes: In these notes, losses are calculated based on published industrywide or geographic indices such as Property Claims Services in the U.S. The ceding insurer has, therefore, some basis risk between its book's performance and index performance. The development period is relatively short, generally less than two years. The calculation is also easy and transparent.

(3) Parametric notes: In these notes, pay-outs are calculated based on mathematical formulas reflecting quantitative attributes of a pertinent peril such as magnitude, intensity, epicentre of an earthquake, wind speed, or forward velocity of a hurricane. Models used in the parametric notes seek to minimize the basis risk between the insured books and the bond structure pay-outs. Loss development period is nearly eliminated. 


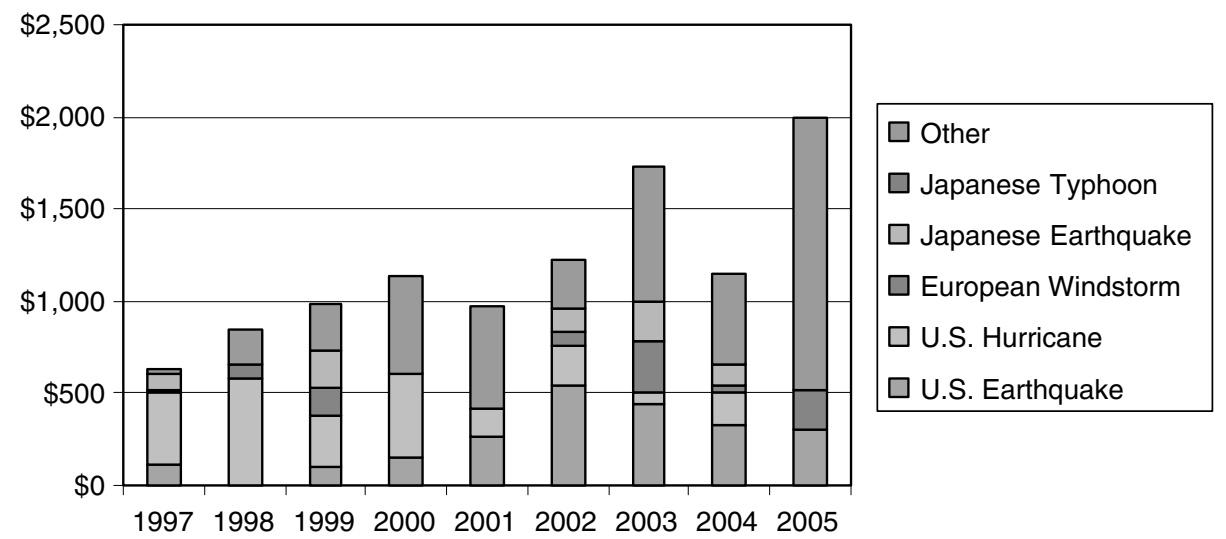

Graph 5. CAT bond issuance.

As indicated in Graph 5, CAT bonds volume has certainly grown since the first issuance in 1997, although this growth has been somewhat erratic. The growth has also come more from larger transactions getting done than the number of deals. In perils such as U.S. Hurricane and U.S. Earthquake, volume by principal amount has actually shrunken over the last four years. More recently, the market has also included some less traditional type of perils, such as $\$ 405$ million of liability insurance sponsored by the Oil Casualty Insurance Corp. in 2005.

\section{Mortality CAT bonds}

Since 2003, there have been three mortality CAT bonds issued by Swiss Re and Scottish Re. These bonds are structured using similar technology as P/C CAT bonds, but the peril is defined in terms of mortality increase against a base case threshold (see Graph 6).

\section{Sidecars}

While CAT bonds function like an excess-of-loss reinsurance layer, whereby investors provide an insurer with coverage above a specified trigger level, sidecar structures function like a quota share agreement, whereby investors participate in a proportion of all of the business within an insurer's defined block of business. One can think of CAT bonds as taking a horizontal layer of the ceding insurer's risk, whereas sidecars offer a vertical layer of risk (see Figure 6).

The benefits to the issuers include the following:

- ability to capture market share during rate hardening;

- providing additional rent income on underwriting expertise;

- collateralized aggregate reinsurance for open indemnity portfolio;

- allowing for exit of excess capital. 
The Geneva Papers on Risk and Insurance - Issues and Practice

56

\begin{tabular}{|c|c|c|c|c|c|}
\hline Year & Issuer & Size ('MM) & Ratings & Attachment Point* & Exhausting Point ${ }^{\star \star}$ \\
\hline 2003 & Vita Capital Ltd. (Swiss Re) & $\$ 250$ & $A+$ & $130 \%$ & $135 \%$ \\
\hline 2005 & Vita Capital II Ltd. (Swiss Re) & $\$ 200$ & $\mathrm{BBB}+\$ 100, \mathrm{BBB}-\$ 100$ & BBB $+115 \%$, BBB- $110 \%$ & BBB $+120 \%$, BBB- $115 \%$ \\
\hline 2006 & Tartan Capital Ltd. (Scottish Re) & $\$ 155$ & A- $\$ 75$, BBB $\$ 80$ & A- $115 \%$, BBB $110 \%$ & A- $120 \%$, BBB $115 \%$ \\
\hline
\end{tabular}

Index Definition:

Vita Capital Ltd.: based on published population mortality in the U.S., France, U.K., Switzerland and Italy

Vita Capital II Ltd.: based on published population mortality in the U.S., Germany, U.K., Japan and Canada

Tartan Capital Ltd.: U.S. population mortality based on Scottish Re portfolio construction

*: First dollar of principal loss begins when mortality as a percent of base case reaches this point

**: $100 \%$ of principal is lost when mortality as a percent of base case reaches this point

Graph 6. Mortality CAT bonds.

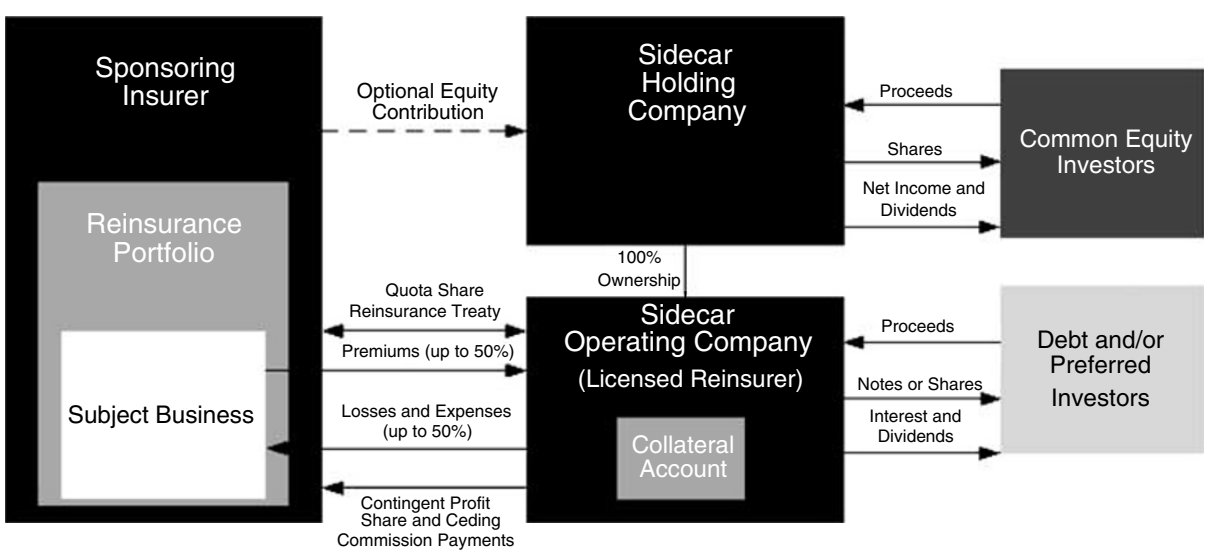

Figure 6. Generic schematic structure of a sidecar.

The benefits to investors include the following:

- opportunistic investment during hard market;

- access to underwriting expertise;

- limited exposure to operating risks and legacy issues;

- pre-determined exit strategy.

\section{Industry Loss Warranties (ILWs)}

ILWs are contractual agreements that call for the seller to pay the buyers on specified type of losses incurred by the buyer if the industry, as measured by published indices, incurred losses as a whole above certain threshold. There are, therefore, two triggers for a pay-out:

- First trigger: The insured loss of the buyer;

- Second trigger: Losses to the insurance industry as a whole. 
The contracts are easy to understand, flexible and can be priced and executed very quickly, even as a peril has already come into existence. Issuer/buyer does not have to disclose underwriting information. Pricing is competitive and indemnity is precise. To the sellers, ILW offers a quick way to get into the market and can be tailored to a seller's risk preference.

\section{Conclusion}

The traditional capital raising markets have shown greater depth and maturity in the past months. This, coupled with continued innovation and growing investor demand in the ILS market, indicates a very healthy future and strong growth for insurance risk in the fixed income capital markets.

This outlook is driving greater investment from investment banks, investors and insurers creating a virtuous circle of development reminiscent of the way the commercial bank market for real risk transfer developed.

UBS is a leading player in this development.

\section{About the Authors}

David Soanes has been with UBS since 1991, holding a series of Capital Market positions. He was Head of Debt Capital Markets in Europe from 2003 after being Head of FIG Debt Capital Markets from 2000. At the start of 2006, he was promoted to Head of FIG for Europe, Middle East and Africa for UBS Investment Bank. He holds an M.A. from Magdalene College, Cambridge University.

Y.C. Wu joined UBS in May 2006. Prior to joining UBS, he was a Director in the Commercial ABS Group of FGIC responsible for FGIC's Financial Institutions business. He joined FGIC in 2004 from MBIA where he also was a Director in the Financial Institutions Group. Prior to MBIA, he worked in the Financial Institutions Group at Goldman Sachs. He has worked on a broad range of capital markets transactions and M\&A advisory assignments for financial institutions and has extensive experience in insurance securitization, including closed block securitization, $\mathrm{EV} / \mathrm{VIF}$ securitization, $\mathrm{XXX} / \mathrm{AXXX}$ securitization, CAT bonds, $12 \mathrm{~b}-1$ fees, commission fees and other insurance-related structured products. He received his JD/MBA joint degree from Stanford Law School and Stanford Graduate School of Business in 1994. 